\title{
Catalytic Decomposition of Tar using Iron Supported Biochar
}

\author{
James R. Kastner*, Sudhagar Mani, Ankita Juneja \\ Biochemical Engineering, College of Engineering \\ The University of Georgia, Athens GA 30602, USA \\ *Corresponding author phone: 706-583-0155; fax: 706-542-8806 \\ e-mail: jkastner@engr.uga.edu
}

\begin{abstract}
Iron supported biochar catalysts were used to decompose toluene, a model tar compound, over a temperature range of $600-900^{\circ} \mathrm{C}$. Toluene conversion and decomposition rates increased linearly with increasing temperature and catalyst loading from 600 to $700^{\circ} \mathrm{C}$. Relative to biochar alone, the iron supported catalysts lowered the activation energy by $47 \%$ and decreased the formation of benzene, an intermediate in toluene decomposition. At $800^{\circ} \mathrm{C}$ for the 13 and 18.7 wt. $\%$ iron loaded catalyst, toluene conversion approached $100 \%$ and benzene selectivity $\left(\mathrm{S}_{\mathrm{B}}\right)$ was zero, compared to an $\mathrm{S}_{\mathrm{B}}$ of $0.025 \%$ and $0.35 \%$ for $10 \%$ iron and the biochar, respectively. Time on stream studies with the 13 wt.\% iron biochar catalyst, over the course of four days, resulted in a mean toluene conversion of $91 \%$ and benzene selectivity of $0.02 \%$. These results indicate that inexpensive iron impregnated biochar catalysts could potentially be used to catalytically decompose tar molecules in syngas generated via biomass gasification.
\end{abstract}

Index Words: Biochar; iron; catalyst; tar; toluene; reforming; synthesis gas 


\section{Introduction}

Gasification and pyrolysis are two technologies that can be used to generate renewable $\mathrm{H}_{2}$, synthesis gas $\left(\mathrm{CO}_{2}, \mathrm{CO}, \mathrm{H}_{2}\right)$, or bio-oils from biomass. The synthesis gas can be catalytically reformed into liquid fuels (e.g., methanol, hydrocarbons), or $\mathrm{H}_{2}$ and used directly in fuel cells (Guell et al., 2014; Parthasarathy and Narayanan, 2014). Bio-oils can, in theory, be converted to fuels and chemicals (Zacher et al., 2014). One of the major drawbacks limiting the use of biomass in both processes is the generation of tar, which can coke downstream reforming, upgrading, Fischer-Tropsch, and fuel cell catalysts, foul other unit operations, and is an environmental hazard (toxic and carcinogenic - Sutton et al., 2001). Tar is typically composed of toluene (24\%), one ringed aromatics other than toluene (22\%), naphthalene (15\%), 2 ringed PAH's other than naphthalene (13\%), 3-4 ringed PAH's (7\%), phenolics (7\%), and heterocyclics (10\%) (Shen and Yoshikawa, 2013). Catalytic removal or transformation of tar to synthesis gas components is the most practical method of solving this problem compared to physical separation or thermal treatment of the tar (Shena and Yoshikawa, 2013).

A wide range of catalysts have been studied for tar removal including, Ni supported catalysts, dolomite, olivine, zeolites, and carbon supported catalysts (Shena and Yoshikawa, 2013). Olivine (a mineral containing magnesium, iron, and silicon) has low surface area $\left(<0.5 \mathrm{~m}^{2}\right.$

$\mathrm{g}^{-1}$ ), typically requires calcination at high temperature (e.g., $900^{\circ} \mathrm{C}$ in air for $10 \mathrm{~h}$ ) and has low activity, which results in lower tar decomposition rates relative to other catalysts (Dayton et al., 2002; Devi et. al., 2005; Shen and Yoshikawa, 2013) and deactivates rapidly due to coke formation and low surface area (Shen and Yoshikawa, 2013). Iron is theorized to be the catalytically active metal in olivine and significant efforts have been explored to increase the surface area and active site density of this metal in olivine (Shen and Yoshikawa, 2013). 
Dolomite $\left(\mathrm{CaMg}\left(\mathrm{CO}_{3}\right)_{2}\right)$, although an effective tar removal catalyst, easily sinters and rapidly deactivates, again leading to a significant reduction in tar removal (Dayton et al., 2002). Zeolites and Ni supported catalysts are more expensive than olivine and dolomite, and coke easily (Dayton et al., 2002; Shen and Yoshikawa, 2013) leading to a significant reduction in tar removal. Key attributes of an effective catalyst for tar removal are low cost, high activity, resistant to coking and poisoning, and ease of regeneration (Dayton, 2002). Only recently have carbon catalysts been studied for tar removal/transformation and may hold advantages over the other catalysts, including high surface area and resistance to coking (Shen and Yoshikawa, 2013).

Biochar produced by slow or fast biomass pyrolysis is an attractive carbon catalyst or support since it is inexpensive, produced from biomass (i.e., lignocellulosics) and not mined, can have high surface area, and contains catalytically active alkali metals which migrate to the surface upon pyrolysis. Recent research indicates that biochar catalytically removes tar components partly due to the presence surface alkali metals such as $\mathrm{Na}, \mathrm{Ca}, \mathrm{K}$ and potentially $\mathrm{Fe}$ (Mani et al., 2013, Abu El-Rub et al., 2008B).

However, tar removal rates using biochar are lower than metal supported catalysts, such as $\mathrm{Ni} /$ olivine and $\mathrm{Ni} /$ dolomite (Xu et al., 2010). Attaching an active metal to the biochar surface may improve biochar catalytic performance. Nickel supported catalysts have been studied extensively and shown to have high tar removal rates, yet rapidly deactivate due to coke deposition and $\mathrm{H}_{2} \mathrm{~S}$ poisoning, and pose an environmental risk upon disposal (Xu et al., 2010). Alternatively, iron, an earth abundant, non-toxic metal, can potentially be used for tar removal. Previous research indicates that iron and iron oxides (hematite, $\mathrm{Fe}_{2} \mathrm{O}_{3}$, reduced to magnetite, $\mathrm{Fe}_{3} \mathrm{O}_{4}$ ) can act to catalytically oxidize tar and ammonia as well (Ohtsuka et al., 2004), potentially 
by promoting steam reforming and the water gas shift reaction. Most research using iron oxide or iron as a tar removal catalyst has been studied using aluminum, olivine, or coal char as a support (Abu El-Rub, 2008A; Ohtsuka et al., 2004; Virginie et al., 2010). Given the limited information on the kinetics of tar removal and longevity of iron loaded catalysts synthesized from biochar, our objectives were to determine the reaction kinetics for catalytic cracking of toluene using iron supported biochar and evaluate the longevity of the catalyst for tar cracking applications.

\section{Materials and Methods}

2.1 Catalyst Preparation: Char was prepared by pyrolyzing pine bark (Southern Pine bark, Waycross, GA) at $950^{\circ} \mathrm{C}$ for 2 hours as described in Mani et al., 2013. Iron loaded biochars were prepared by dissolving 16 grams of ferric nitrate [ $\mathrm{Fe}\left(\mathrm{NO}_{3}\right)_{3} \cdot 9 \mathrm{H}_{2} \mathrm{O}$; Sigma Aldrich, $98^{+} \%$ ] in 20 $\mathrm{ml}$ of acetone, and subsequently mixing 20 and 15 grams of char respectively ( $\sim 9$ and 13 wt. \% Fe). An additional type of catalyst was prepared by dissolving 24 grams of ferric nitrate in $30 \mathrm{ml}$ of acetone and adding 12 grams of char $(18.7 \mathrm{wt} . \% \mathrm{Fe})$. The biochars were contacted with the iron nitrate solution for 30 minutes, until there was no excess liquid, and subsequently dried at $105^{\circ} \mathrm{C}$ (air) for 8 hours. The dried samples were calcined at $300^{\circ} \mathrm{C}$ for one hour in a furnace with air flow of $10 \mathrm{~L} / \mathrm{min}$.

2.2 Catalyst Characterization: The physical and chemical characteristics of biochar and iron loaded biochar was determined and included surface area, pore size distribution (BET and BJH 
methods, using a Quantachrome Autosorb 1C, Quantachrome, Boynton Beach FL), and elemental composition as described in Mani et al. (2013).

X-ray diffraction (XRD) analyses were performed with a Scintag XDS 2000 diffractometer equipped with a cobalt X-ray tube. Powdered samples were mounted on quartz plates and stepped scanned over the angular range $15-50^{\circ} 2 \theta$. The step size for the analysis was $0.01^{\circ} 2 \theta$ with a count time of 10 s/step. All crystalline phases were identified based on comparison of the observed data with a reference database of crystalline materials produced by the International Center for Diffraction Data (ICDD). In this study a scanning electron microscope (SEM-EDS, FEI Inspect F FEG-SEM equipped with EDAX-EDS, EDAX is energy dispersive analysis of X-rays) was used to image the biochars. Prior to scanning, the powdered samples were coated with gold and spread out on a scanning plate and EDAX-EDS used to determine the elemental composition and mapping of the surface. Quantitation was achieved by comparing the X-ray yields from the sample with yields obtained from standards and ZAF ( $\mathrm{Z}=$ =element number, $\mathrm{A}=$ absorption, $\mathrm{F}=$ secondary fluorescence) correction was applied for bulk sample analysis using the following equation, $\mathrm{C}_{\text {spec }} / \mathrm{C}_{\text {std }}=\mathrm{k} \mathrm{Z} \mathrm{A} \mathrm{F} \mathrm{c.} \mathrm{Where,} \mathrm{C}_{\text {spec }}$ is the element concentration in the catalyst sample or specimen, $\mathrm{C}_{\text {std }}$ is the concentration of the element in the standard, $\mathrm{Z}$ is the atomic correction factor, $\mathrm{A}$ is the absorption correction factor, $\mathrm{F}$ and $\mathrm{c}$ are secondary fluorescence corrections for bremsstrahlung and continuum radiation respectively, and $\mathrm{k}$ is ratio of X-ray intensity (I) for the specimen to standard; $\mathrm{k}=\mathrm{I}_{\mathrm{sped}} / \mathrm{I}_{\mathrm{std}}$ (Niemantsverdriet, 2000; Newbury and Ritchie, 2013).

2.3 Catalyst Testing: The catalytic conversion of toluene was studied in a previously 
described continuous flow packed bed reactor system at different temperatures $\left(400-900^{\circ} \mathrm{C}\right)$ and atmospheric pressure. Nitrogen was used as the carrier gas $\left(700 \mathrm{ml} \mathrm{min}^{-1}\right)$ and streams of toluene and water were added to the main flow by two syringe pumps. Toluene was injected using a stainless steel syringe (Cole-Parmer-74900 series, $60 \mathrm{ml}$ ) and water was added using a syringe (Becton Dickinson Plastipak $60 \mathrm{ml}$, Luer lok tip). The nitrogen, toluene and water mixture were then passed through a static mixer (stainless steel, length $-0.53 \mathrm{~m}$, o.d. $0.006 \mathrm{~m}$ ) and then transported down the reactor (stainless steel, length $0.6 \mathrm{~cm}$, i.d. $0.025 \mathrm{~m}$ ), enclosed in a furnace (Lindberg Blue M), containing a $0.45 \mathrm{~m}$ preheating zone, followed by $0.03 \mathrm{~m}$ of catalyst supported by a steel wire mesh (0.025 m i.d.) and quartz wool (Leco fine quartz wool; $3.8 \mathrm{~g}$ catalyst or biochar). Previous details concerning the reactor set-up and conditions implemented during catalytic testing have been published (Mani et al., 2013).

2.4 Mass Transfer Effect Calculations: Given the small particle size range of the catalysts (0.2-0.4 mm), medium range surface area (180-350 vs. $1000-1500 \mathrm{~m}^{2} \mathrm{~g}^{-1}$ for activated carbon) and pore volume (Table 1), we did not expect that external or internal mass transfer would limit toluene decomposition and falsify our kinetic analysis. Additional evidence is presented to indicate that external and internal mass transfer were not rate limiting and thus criterion for external (eq. 1) and internal diffusion (eq. 3) were calculated (Fogler, 1986).

\section{External Effects:}

According to the Mear's criterion (eq. 1) if the calculated value is less than 0.15 , external mass transfer effects can be neglected. 


$$
\frac{r_{\text {Toluene }} \rho_{b} R n}{k_{c} C_{\text {Toluene }}}<0.15
$$

where, $r_{\text {Toluene }}$ is the measured reaction rate $\left(\mathrm{mol} \mathrm{g}^{-1} \mathrm{~s}^{-1}\right), \rho_{\mathrm{b}}$ is the packing density of the catalyst bed $\left(\mathrm{g} \mathrm{m}^{-3}\right), \mathrm{R}$ is the catalyst particle radius (in $\mathrm{m}$; in this case we used a particle diameter, $\mathrm{d}_{\mathrm{p}}=$ $1000 \mu \mathrm{m}$ or $\left.\mathrm{R}=5 \times 10^{-4} \mathrm{~m}\right), n$ the reaction order, $\mathrm{k}_{\mathrm{c}}\left(\mathrm{m} \mathrm{s}^{-1}\right)$ the mass-transfer coefficient shown in eq. $2, \mathrm{D}_{\mathrm{AB}}$ the effective diffusivity of toluene in $\mathrm{N}_{2}\left(4.24 \times 10^{-5} \mathrm{~m}^{2} \mathrm{~s}^{-1}, 823{ }^{\circ} \mathrm{K}\right.$; estimated using the Wilke-Lee equation (Treybal, 1980), Re the Reynolds number based on the particle size, Sc the Schmidt number, and $\mathrm{C}_{\text {Toluene }}$ the bulk gas phase concentration $\left(\mathrm{mol} \mathrm{m}^{-3}\right)$.

$$
k_{c}=0.6\left(\frac{D_{A B}}{d_{p}}\right) \operatorname{Re}^{1 / 2} S c^{1 / 3}
$$

The Mear's criterion for the highest reaction rate data $\left(4500 \mathrm{ppmv}\right.$ toluene, $550{ }^{\circ} \mathrm{C}, 19$ wt. $\% \mathrm{Fe}-$ biochar) ranged between $0-0.007$, significantly less than 0.15 (for $\mathrm{k}_{\mathrm{c}}=0.02-0.5 \mathrm{~m} \mathrm{~s}^{-1}, n$ or reaction order $=1-1.5$, and $\left.d_{p} 0-1 \mathrm{~mm}\right)$, indicating external mass transfer limitations did not occur.

\section{Internal Effects:}

SEM and BET analysis of the biochar and iron supported char clearly indicated a surface area and pore structure in the material used in our experiments (Fig. 1 and Table 1 ), suggesting possible internal mass transfer resistance (Mani et al., 2013). Thus, the Wiesz-Prater criterion $\left(\mathrm{C}_{\mathrm{WP}}\right)$, eq. 3, was used to estimate the effect of internal mass transfer in the reactions with the iron supported catalysts (Fogler, 1986), where a $\mathrm{C}_{\mathrm{WP}}<<1$ indicates that internal mass transfer resistance can be ignored. 


$$
C_{W P}=\frac{-r_{\text {Toluene }} \rho_{p} R^{2}}{D_{e} C_{\text {Toluenes }}}
$$

The Wiesz-Prater criterion $\left(\mathrm{C}_{\mathrm{WP}}\right)$ was estimated to be 0.0-0.2 (much smaller than 1 ) for biohcar and the iron supported catalysts $\left(d_{p}=0-1 \mathrm{~mm} ; \mathrm{R}=\mathrm{d}_{\mathrm{p}} / 2\right)$, utilizing measured reaction rate data, the measured catalyst packing density $\left(\rho_{\mathrm{p}}\right)$, the concentration of toluene at the surface $\left(\mathrm{C}_{\mathrm{Toluene}, \mathrm{s}}\right)$ and an estimated effective diffusivity, $\mathrm{D}_{\mathrm{e}}\left(\sim 1-2 \times 10^{-8} \mathrm{~m}^{2} \mathrm{~s}^{-1}\right)$. The effective diffusivity was estimated from the toluene- $\mathrm{N}_{2}$ diffusion coefficient $\left(\mathrm{D}_{\mathrm{eff}}\right.$, Toluene $)$ and Knudsen diffusion or $\mathrm{D}_{\mathrm{K}, \text { Toluene }}$ (eqs. 4 and 5), and the temperature $(T, K)$, gas constant $\left(R_{\text {gas }}\right)$, molecular weight of toluene $\left(M_{A}\right)$, estimated particle porosity $(\varepsilon=0.2-0.5)$ and tortuosity factor $(\tau=2-6$ for activated carbon $)$ of the biochar from literature analysis (Treybal, 1980; Lua and Yang, 2009). The specific particle

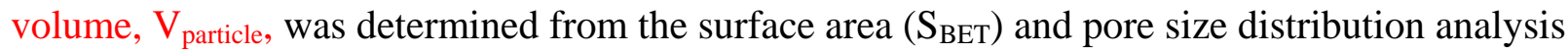
$\left(\mathrm{V}_{\text {particle }}=\varepsilon / \mathrm{S}_{\mathrm{BET}}\right)$. We neglected surface diffusion in this analysis.

$$
\begin{aligned}
& D_{\text {eff }, \text { Toluene }}=\frac{\varepsilon_{\text {particle }}}{\tau_{\text {particle }}}\left(\frac{1}{\left.\frac{1}{D_{{\text {Toluene } N_{2}}}+\frac{1}{D_{K, \text { Toluene }}}}\right)}\right. \\
& D_{K, \text { Toluene }}=\frac{4}{3} \frac{\varepsilon_{\text {particle }}}{S_{B E T} \rho_{\text {particle }}} \sqrt{\frac{8 R_{\text {gas }} T}{\pi M_{A}}}=\frac{4}{3} \frac{V_{\text {particle }}}{S_{B E T}} \sqrt{\frac{8 R_{\text {gas }} T}{\pi M_{A}}}
\end{aligned}
$$

2.5 Temperature Effect and Kinetic Calculations: Using a continuous flow catalytic test bed (3.8 $\mathrm{g}$ biochar, $2500 \mathrm{ppmv}, 0.7 \mathrm{~L} \mathrm{~min}^{-1}$ ), the effect of temperature on toluene conversion and benzene selectivity was determined at temperatures ranging from 400 to $900^{\circ} \mathrm{C}$. Toluene conversion was measured using equation 6 , 


$$
X=\frac{C_{T, \text { in }}-C_{T, \text { out }}}{C_{T, \text { in }}}
$$

where, $\mathrm{X}=$ toluene conversion, $\mathrm{C}_{\mathrm{T} \text {,in }}=$ inlet toluene concentration, and $\mathrm{C}_{\mathrm{T} \text {,out }}=$ outlet toluene concentration.

The selectivity of benzene $S_{B}$ was calculated according to eq. (7),

$$
S_{B}=\frac{\left[C_{B}\right]_{\text {out }}}{\left[C_{T, \text { in }}-C_{T, \text { out }}\right]} * 100
$$

where, $\left[\mathrm{C}_{\mathrm{B}}\right]$ is the molar flow rate of benzene in the products. These parameters were reported as the average of 8 steady-state sample analysis and 3 replicates.

Comparison of toluene kinetics between biochar and the iron supported biochar were determined by holding the residence time $(3.8 \mathrm{~g}$ biochar, $0.7 \mathrm{~L} / \mathrm{min})$ and temperature constant (biochar- $550,600,650,700^{\circ} \mathrm{C}$; Fe-biochar $400,450,500,550^{\circ} \mathrm{C}$ ) and varying the inlet toluene concentration. A plug flow, constant volumetric flow rate, differential reactor was assumed and subsequently the reaction rate was calculated based on the inlet molar rate, fractional toluene conversion, and catalyst mass according to eq. 8 . Where $-\mathrm{r}_{\mathrm{T}}$ is the toluene removal rate, $\mathrm{F}_{\mathrm{Ao}}$ the inlet molar flow rate of toluene, $\mathrm{W}$ the catalyst mass, and $\mathrm{X}$ the fractional conversion of toluene across the catalytic bed.

$$
-r_{T}=\frac{F_{A o} X}{\Delta W}
$$

Using reaction rate data, a pseudo-order rate law (eq. 9) was fit to the data to determine the reaction rate constant and order,

$$
-r_{T}=k C_{T}^{n}
$$


where, $k=$ rate constant, $C_{T}=$ concentration of toluene in the inlet, $n$ the order of the reaction with respect to toluene, since steam was added in excess of the toluene stoichiometric requirement where, $\mathrm{k}=k^{\prime} C_{\mathrm{H}_{2} \mathrm{O}}^{m}$, resulting in a reaction rate independent of $C_{\mathrm{H}_{2} \mathrm{O}}$ (Li et al., 2009; Swierczynski et al., 2008).

The activation energy, $\mathrm{E}_{\mathrm{a}}$, for toluene decomposition was determined by holding the space velocity $\left(0.09 \mathrm{~kg} \mathrm{~h} \mathrm{~m}^{-3}\right)$ and inlet concentration $(\sim 2,500 \mathrm{ppmv})$ constant and varying the temperature from $400-700^{\circ} \mathrm{C}$. Under these conditions the rate constant, $\mathrm{k}$, was determined using equation 10 , where $\mathrm{X}$ is fractional toluene conversion, $\mathrm{W}_{\text {cat }}$ is catalyst mass, and $\mathrm{Q}$ is volumetric flow rate. The rate constant values were then fit to the Arrhenius equation to determine the activation energy.

$$
k=\frac{-\ln (1-X)}{W_{c a t} / Q}
$$

Analytical and Characterization Methods: The physical and chemical characteristics of the biomass and biochar, including $\mathrm{pH}$, surface area, bulk density, and the elemental composition were previously determined (Kastner et al., 2009). Toluene and benzene were identified using a GC/MS (Model HP-6890 GC and a Model HP-5973 mass selective detector with a scan range from 20-350 mass units, using the same column and method as GC/FID analysis) and quantified using a GC/FID (HP 5890 series II, HP-5 MS capillary column, 30 m X 0.25 $\mu \mathrm{m}$, diameter 0.25 $\mathrm{mm})$. The compounds were identified using the GC/MS and Agilent Technologies software (MSD ChemStation D.03.00.611), which uses a probability-based matching (PBM) algorithm to match unknown spectra to those found in a mass spectral library using National Institute of Standards and Technology's 2008 version (NIST 2008). In the GC/FID method, helium was 
used as the carrier gas $(2 \mathrm{ml} / \mathrm{min})$ and analysis was performed under isothermal conditions (oven temperature $50^{\circ} \mathrm{C}$, detector $220^{\circ} \mathrm{C}$ and injection port $200^{\circ} \mathrm{C}$ ) with a $200 \mu \mathrm{l}$ injection volume. Benzene and toluene were identified on the GC/FID by matching retention times with neat standards. Standard curves for toluene and benzene (10 point) were prepared from neat liquids (Sigma-Aldrich, purity 99\%) over a range of 50-5000 ppmv.

\section{Results and Discussion}

\subsection{Catalyst Characterization: Analysis of the biochar via SEM did indicate an ordered} honeycomb type structure in the biochar and subsequent iron impregnation and calcination did lead to the formation of iron particles on the surface of the biochar. This is noticeable in the SEM images (Fig. 1A and B) and was confirmed by EDS analysis (Fig. 2). EDS analysis indicated no measurable iron on the surface of the biochar $\left(950^{\circ} \mathrm{C}\right)$, but measured $12 \mathrm{wt} . \%(9 \mathrm{wt} . \%$ via elemental analysis or EA) and 55 wt.\% (13 wt.\% via EA) respectively, on isolated portions of selected catalyst particles (Fig. 2). We believe this large difference between EDS and EA analysis for the 13 wt.\% Fe-biochar was due to the limited number of samples and very small area we could analyze using SEM-EDX. The 55 wt.\% iron result in the area analyzed was probably due to very localized agglomeration and minimal iron dispersion. EDS analysis also indicated the presence of potassium on the surface (2.0-12 wt.\% for biochar only and $0.5 \mathrm{wt} . \%$ for the 9 wt.\% Fe-biochar via SEM-EDS, data not shown) originating from the starting biomass used to generate the biochar (Mani et al., 2013), suggesting this alkali metal may have acted as a catalyst promoter in the presence of the iron. 
XRD analysis of the iron impregnated biochar after calcination indicated that no clearly observable crystalline phases formed (e.g., $\mathrm{Fe}_{3} \mathrm{O}_{4}$ or $\mathrm{Fe}_{2} \mathrm{O}_{3}$ ), suggesting an amorphous iron phase was formed on the carbon surface (data not shown). Iron impregnation and subsequent calcination reduced the surface area and pore volume by $24 \%\left(320 \pm 10.26 \mathrm{~m}^{2} / \mathrm{g}\right.$ for biochar compared to $244.2 \pm 82.7 \mathrm{~m}^{2} / \mathrm{g}$ for all of the Fe-biochars) and $29 \%\left(0.17 \mathrm{~cm}^{3} / \mathrm{g}\right.$ for biochar and $0.12 \pm 0.042 \mathrm{~cm}^{3} / \mathrm{g}$ for all of the Fe-biochar) respectively, and did not change the average pore size (10.04 $\AA$ for biochar and $10.6 \pm 0.2 \AA$ for all Fe-biochars; Fig. 1 and Table 1). The reduction in pore volume was most noticeable in the reduction of pores of the $16-20 \AA$ radius range observed in the BJH plots (Fig. 1C). Pore sizes ranging from 8-16 $\AA$ (radius) were not observed in the biochar and Fe-biochar, as compared to a commercial carbon (Fig. 1C and D). These results indicate that the relatively high surface area $\left(244.2 \pm 82.7 \mathrm{~m}^{2} / \mathrm{g}\right)$, mesopore size distribution ( 10-40 A radius for all Fe-biochars), and increased alkali metal content of the pine bark biochar (Mani et al., 2013) were responsible for a portion of the catalytic activity.

\subsection{Activation Energy and Kinetics: It is clear that iron impregnation of the biochar resulted} in a significant increase in catalytic activity at lower temperatures relative to biochar alone. For example, at a constant temperature of $600^{\circ} \mathrm{C}$, increasing the iron loading to $\sim 19 \mathrm{wt} . \%$ generated a toluene conversion of $\sim 50 \%(46 \pm 0.5)$ compared to $\sim 14 \%$ (13.7 \pm 0.83$)$ for biochar (Fig. 3). Similarly, iron biochar resulted in a toluene reaction rate of $8.2 \pm 4.1 \times 10^{-3}$ moles g $^{-1} \mathrm{~s}^{-1}$ compared to no measurable reaction rate at $400^{\circ} \mathrm{C}$ for biochar alone (Fig. 3B). The rate of toluene decomposition and conversion was also observed to increase linearly with catalyst loading over a small temperature range of 600 to $700^{\circ} \mathrm{C}$ (Fig. 3 inset, part A). Finally, the effect 
of iron impregnation on catalytic activity was most noticeable in an Arrhenius plot and the observed lower activation energy $\left(\mathrm{E}_{\mathrm{A}}\right)$ of the iron impregnated biochar. Assuming first order kinetics at a fixed toluene inlet concentration of 2,500 ppmv, we measured a $47 \%$ reduction in the activation $\left(\mathrm{E}_{\mathrm{A}}\right)$ for biochar catalyst with $18.7 \mathrm{wt} . \%$ iron loading relative to biochar alone (Fig. 4). We note that at concentrations lower than $2,500 \mathrm{ppmv}\left(<40 \times 10^{-6}\right.$ moles $\left.\mathrm{L}^{-1}\right)$, the kinetics of toluene decomposition for the iron impregnated biochar was first order (Fig. 5).

Rate constants, in the apparent first order region calculated using equation 10, and activation energies were tabulated and compared with the literature performed under similar conditions (Table 2$)$. The iron/biochar catalyst ( 19 wt.\% Fe) toluene decomposition activity was comparable to, or higher (lower activation energy and higher rate constant) than olivine or nickel supported catalysts (Table 2). In work with olivine, Devi 2005, noted that calcination in air at $900^{\circ} \mathrm{C}$ significantly increased catalytic activity primarily due to movement of iron to the surface possibly due to the formation of hematite and other forms of Fe with incorporated $\mathrm{Mg}$ (however, with little change in surface area). The active form of the iron in our work is unclear, since XRD analysis could not confirm the presence of iron oxides $\left(\mathrm{Fe}_{2} \mathrm{O}_{3}\right.$ - hematite and $\mathrm{Fe}_{3} \mathrm{O}_{4}$ magnetite) in the fresh catalyst (data not shown) and calcination was performed at $300^{\circ} \mathrm{C}$. Used catalyst was also characterized; however, we could not confirm the presence of reduced iron or other crystalline iron phases via XRD. We speculate that amorphous iron oxides were initially formed after calcination (e.g., $\mathrm{FeOOH})$ and subsequently reduced to metallic iron $\left(\mathrm{Fe}^{\mathrm{o}}\right)$ or other forms of more reduced iron (e.g., FeO) via hydrogen formed during steam reforming of toluene catalyzed by carbon and alkali metals in the biochar or by direct reaction with carbon. A wide range of iron supported catalysts (olivine, limonite $[\mathrm{FeOOH}], \mathrm{FeO}, \mathrm{Fe}_{2} \mathrm{O}_{4}, \mathrm{Fe}_{3} \mathrm{O}_{4}$, and $\mathrm{Fe}_{2} \mathrm{O}_{3}$ ) have been demonstrated to catalytically decompose tar (Xu et al. 2010). However, evidence in 
the literature suggests that the iron oxides are reduced to elemental iron by hydrogen (at the appropriate temperature) generating the true catalytically active metal, $\mathrm{Fe}^{\mathrm{o}}$ (Nordgreen et al., 2006).

Having confirmed biochar and the iron supported catalyst were catalytically active for toluene decomposition, the kinetics of the reaction was measured (Mani et al., 2013). At a constant space velocity and temperature, increasing the inlet toluene concentration resulted in a linear increase in the measured reaction rate (eq. 6) indicating a first order reaction for biochar (Mani et al., 2013). However, under similar conditions a non-linear response to an increase in the toluene concentration was observed in the measured reaction rate for the iron supported biochar catalyst (Fig. 5). As toluene concentration was increased, the reaction rate approaches zero order (independent of toluene concentration). The shift in the reaction order suggests that the apparent rate law is no longer independent of water vapor concentration, due to higher catalytic activity of the iron biochar and increased toluene concentration (Fig. 5).

\subsection{Reaction Products: GC/MS analysis of the outlet clearly identified benzene via mass} spectral matching. Subsequently, benzene was quantified based on retention time matching and a standard curve using the GC/FID system. For biochar alone, benzene selectivity, $\mathrm{S}_{\mathrm{B}}$, increased from 0 to $0.25-0.30$ with increasing temperature $\left(600-800^{\circ} \mathrm{C}\right)$ and fractional conversion of toluene, but did not increase beyond $800^{\circ} \mathrm{C}$ (Fig. 6A). Contrary to biochar alone, benzene selectivity declined with increasing reaction temperature and never increased above 0.2 for the iron supported biochar (Fig. 6A). 


\subsection{Catalyst Longevity (Time on Stream): Long-term catalytic tests for toluene}

decomposition using 13 wt.\% iron impregnated biochar was conducted $\left(800^{\circ} \mathrm{C}, 0.09 \mathrm{~kg}_{\mathrm{cat}}-\mathrm{hr} \mathrm{Nm}^{-}\right.$

${ }^{3}, 2500$ ppmv, Steam/Carbon = 3) for 3 days, to confirm potential industrial application. The results demonstrated that the iron biochar maintained toluene fractional conversion at $100 \%$ for 16 hours and then suddenly the fractional conversion decreased to $40 \%$ (Fig. 6B). Benzene selectively increased concomitantly with the decrease in toluene conversion up to 30 hours (Fig. 6B). The decline in catalytic activity may have been due iron sintering. SEM-EDX mapping did indicate a clustering of iron atoms after a short time, based on previous sub-sampling and analysis of recovered catalyst (Fig. 2, compare B and C).

After the decline in toluene conversion, there was a sudden increase in toluene conversion (and decrease in benzene selectivity) which remained at $100 \%$ conversion for 40 hours (Fig. 6B). This is hard to explain. One possibility is the formation of coke which reportedly increases tar decomposition on alumina catalyst (Hosokai et.al., 2005) and/or the reduction of the iron oxides to elemental iron which is reportedly active for catalytic steam reforming and the water-gas shift reaction (Nordgreen et al., 2006). SEM analysis of iron biochar catalyst collected at the end of the run indicated the formation of coke (data not shown). Finally, a similar pattern did appear to start again at the $84 \mathrm{~h}$ mark before ending the experiment. These results demonstrate that the iron impregnated biochar catalyst is capable of long term catalytic activity ( $\sim$ days) resulting in a higher mean toluene conversion and lower mean benzene selectivity compared to biochar alone (Mani et al., 2013).

\section{Conclusions}


Iron impregnated/calcined biochar clearly increased the toluene decomposition rate, lowered the activation energy, and reduced the formation of benzene during toluene steam reforming, all relative to a biochar base catalyst. SEM coupled with EDX analysis confirmed iron deposition on the biochar with a small reduction in surface area and pore volume, yet the active form of iron could not be clearly identified due to inconclusive XRD analysis results. Conclusive evidence that the deposited iron was catalytically active included 1) a significant reduction in activation energy, 2) increasing toluene reaction rate with increasing catalyst loading, and 3) a shift in reaction order at higher toluene concentrations. Our results indicate the feasibility of using iron functionalized biochars as tar reforming catalysts in biomass gasification processes.

\section{Acknowledgements}

The authors graciously thank Joby Miller, Roger Hilten, and Andrew Smola for their invaluable contributions of time and effort in analyzing materials and gaseous compositions. The financial support for this study provided by DOE (DEFG3608GO8814: Biorefining and Carbon Cycling Program) and a University of Georgia Research Foundation (UGARF) startup grant was highly appreciated.

\section{List of Tables}

Table 1: Compositional analysis of biochar and iron supported catalysts.

Table 2. Effect of temperature on fractional conversions and first order rate constants for toluene decomposition using pine bark biochar catalyst (2,500 ppmv inlet, $\left.0.09 \mathrm{~kg} \mathrm{hr} \mathrm{m}^{-3}\right)$ and comparison with the literature. 


\section{List of Figures}

Figure 1: SEM analysis of biochar catalyst generated from pine bark by slow pyrolysis at $950^{\circ} \mathrm{C}$ (A, taken from Mani et al., 2013), resultant iron impregnated catalyst (B-18.7 wt.\% $\mathrm{Fe}$ ) and BJH analysis of the biochar (C) compared to activated carbon (D). The activated carbon was a MeadWestvaco granular carbon (Nuchar WV-B 20) with a surface area of 1944 $\mathrm{m}^{2} / \mathrm{g}$ and presented for comparison purposes.

Figure 2: SEM images and elemental mapping via EDX of biochar and iron supported biochar - A) biochar, B) 13 wt.\% Fe-biochar unreacted, C) 13 wt.\% Fe-biochar reacted at $800^{\circ} \mathrm{C}$ (2,500 ppmv, $3.8 \mathrm{~g}$ biochar, $\left.0.09 \mathrm{~kg}_{\text {cat }} \mathrm{h} \mathrm{m}^{-3}\right)-\mathrm{C}$, carbon; $\mathrm{K}$, potassium; Fe, iron.

Figure 3: Effect of iron loading on toluene decomposition conversion (A) and rates (B) biochar; $\nabla, 10$ wt. \%; $\mathbf{\Delta}, 13$ wt.\%, and $\square, 18.7$ wt.\% Fe-biochar) - inlet toluene concentration $1395 \pm 72$ ppmv for Fe-biochar and $1220 \pm 63$ ppmv for biochar in comparison of rates (B) and 2,500 ppmv for fractional conversion (A), catalyst $3.8 \mathrm{~g}$, space time $=0.09$ $\mathrm{kg}-\mathrm{hr} \mathrm{m}^{-3}$ (inset for part A).

Figure 4: Effect of iron on the activation energy of the apparent first order rate constant for toluene decomposition using $18.7 \%$ iron supported biochar, $\left(\square, E_{A}=48.4 \pm 5.4\right.$ (stnd. error) $\mathrm{kJ} / \mathrm{mole}$ ) compared to biochar only $\left(\boldsymbol{O}, \mathrm{E}_{\mathrm{A}}=91 \pm 17.3\right.$ (stnd. error) $\mathrm{kJ} / \mathrm{mole}$; data taken from Mani et al., 2013) - $3.8 \mathrm{~g}$ catalyst, $0.7 \mathrm{~L} / \mathrm{min}, \sim 2,500 \mathrm{ppmv}$ inlet.

Figure 5: Effect of toluene concentration on the reaction rate for $18.7 \mathrm{wt} . \%$ iron loaded catalyst at different temperatures. In some cases error bars are not visible and smaller than the symbols $\left(\bigcirc 400^{\circ} \mathrm{C}, \square 450^{\circ} \mathrm{C}, \diamond 500^{\circ} \mathrm{C}\right.$, and $\left.\triangle 550^{\circ} \mathrm{C}\right)$.

Figure 6: Effect of iron loading (wt.\%) on toluene conversion and benzene selectivity (A-nitrogen flow $0.7 \mathrm{~L} / \mathrm{min}$, toluene inlet $\sim 2500 \mathrm{ppmv}$, biochar as catalyst $3.8 \mathrm{~g}$, space time $=0.09 \mathrm{~kg}_{\text {cat }} \mathrm{h} \mathrm{m}^{-3}$ ) and time on stream toluene decomposition activity and benzene selectivity for Fe-biochar, 13 wt.\% Fe at $800^{\circ} \mathrm{C}\left(\mathrm{B}-2,500 \mathrm{ppmv}, 3.8 \mathrm{~g}\right.$ biochar, $\left.0.09 \mathrm{~kg}_{\mathrm{cat}} \mathrm{h} \mathrm{m}^{-3}\right)$.

\section{References}

1. Abu El-Rub, Z., Bramer, E., Brem, G., 2008A. Experimental comparison of biomass chars with other catalysts for tar reduction. Fuel 87, 2243-2252. 
2. Abu El-Rub, Z., 2008B. Biomass char as an in-situ catalyst for tar removal in gasification systems. PhD Dissertation. University of Twente, The Netherlands.

3. Dayton, D., 2002. A review of the literature on catalytic biomass tar destruction. US DOE NREL Report Golden, CO, 510-32815.

4. Devi, L., Ptasinski, K., and Janssen, F., 2003. A review of the primary measures for tar elimination in biomass gasification processes. Biomass and Bioenergy 24:125-140.

5. Devi, L., Craje, M., Thune, P., Ptasinski, K.J., Janssen, F. Olivine as tar removal catalyst for biomass gasifiers: Catalyst characterization. Applied Catalysis A: General 294 (2005A) 6879.

6. Devi, L. Catalytic removal of biomass tars; olivine as prospective inbed catalyst for fluidized-bed biomass gasifiers. Eindhoven, The Netherlands: Technical University of Eindhoven; 2005B.

7. Fogler, H. S. Elements of Chemical Reaction Engineering; Prentice-Hall: Englewood Cliffs, NJ, 1986;Chapters 10 and 11.

8. Guell, B.M.; Sandquist, J.; Sørum, L. Gasification of Biomass to Second Generation Biofuels: A Review. Journal of Energy Resources Technology, ASME, 2013, Vol. 135.

9. Hosokai, S., Hayashi, J.-I., Shimada, T., Kobayashi, Y., Kuramoto, K., Li, C.-Z., Chiba, T. Spontaneous generation of tar decomposition promoter in a biomass steam reformer. Chemical Engineering Research and Design, 2005, 83(9A), 1093-1102.

10. Kastner, James R., Miller, Joby., Das, K.C. 2009. Pyrolysis conditions and ozone oxidation effects on ammonia adsorption in biomass generated chars. Journal of Hazardous Materials, $164,2-3,1420-1427$.

11. Lua, A.C., Yang, T. 2009. Theoretical Analysis and Experimental Study on $\mathrm{SO}_{2}$ Adsorption onto Pistachio-nut-shell Activated Carbon. AIChE Journal, 55, 2, 423-433.

12. Li, C., Hirabayashi, D., Suzuki, K. Development of new nickel based catalyst for biomass tar steam reforming producing $\mathrm{H}_{2}$-rich syngas, Fuel Processing Technology 90 (2009) 790-796.

13. Mani, S., Kastner, J.R., Juneja, A. Catalytic decomposition of toluene using a biomass derived catalyst. Fuel Processing Technology 2013, 114, 118-125.

14. Newbury, D.E., Ritchie, N.W.M. Is Scanning Electron Microscopy/Energy Dispersive X-ray Spectrometry (SEM/EDS) Quantitative? SCANNING, 35, 141-168 (2013).

15. Niemantsverdriet, J.W. Spectroscopy in Catalysis: An Introduction. Chapter 7: Microscopy 
and Imaging. Second, Completely Revised Edition. Wiley-VCH, New York. 2000.

16. Nordgreen, T., Liliedahl, T., Sjostrom, K. 2006. Metallic iron as a tar breakdown catalyst related to atmospheric, fluidised bed gasification of biomass. Fuel 85 (2006) 689-694.

17. Ohtsuka, Y., Xu, C., Kong, D. Tsubouchi, N. 2004. Decomposition of ammonia with iron and calcium catalysts supported on coal chars. Fuel 83, 685-692.

18. Parthasarathy, P.; K. Narayanan, K.S. Hydrogen production from steam gasification of biomass: Influence of process parameters on hydrogen yield: A review. Renewable Energy 66 (2014) 570-579.

19. Shen, Y.; Yoshikawa, K. Recent progresses in catalytic tar elimination during biomass gasification or pyrolysis-A review. Renewable and Sustainable Energy Reviews 21 (2013) 371-392.

20. Sutton, D., Kelleher, B., and Ross, J., 2001. Review of literature on catalysts for biomass gasification. Fuel Processing Technology 73:155-173.

21. Swierczynski, D., Courson, C., Kiennemann, A., 2008. Study of steam reforming of toluene used as model compound of tar produced by biomass gasification. Chemical Engineering \& Processing: Process Intensification 47, 508-513.

22. Treybal, R.E. Mass Transfer Operations $3^{\text {rd }}$ Edition; McGraw-Hill New York, 1980.

23. Virginie, M., Courson, C., Kiennemann, A. 2010. Toluene steam reforming as tar model molecule produced during biomass gasification with an iron/olivine catalyst. C. R. Chimie $13,1319-1325$.

24. Xu, C., Donald, J., Byambajav, E., Ohtsuka, Y. 2010. Recent advances in catalysts for hotgas removal of tar and $\mathrm{NH}_{3}$ from biomass gasification. Fuel 89, 1784-1795.

25. Zacher, A.H.; Olarte, M.V.; Santosa, D.M.; Elliott, D.C.; Jones, S.B. A review and perspective of recent bio-oil hydrotreating research. Green Chem., 2014, 16, 491. 
Table 1: Compositional analysis of biochar and iron supported catalysts.

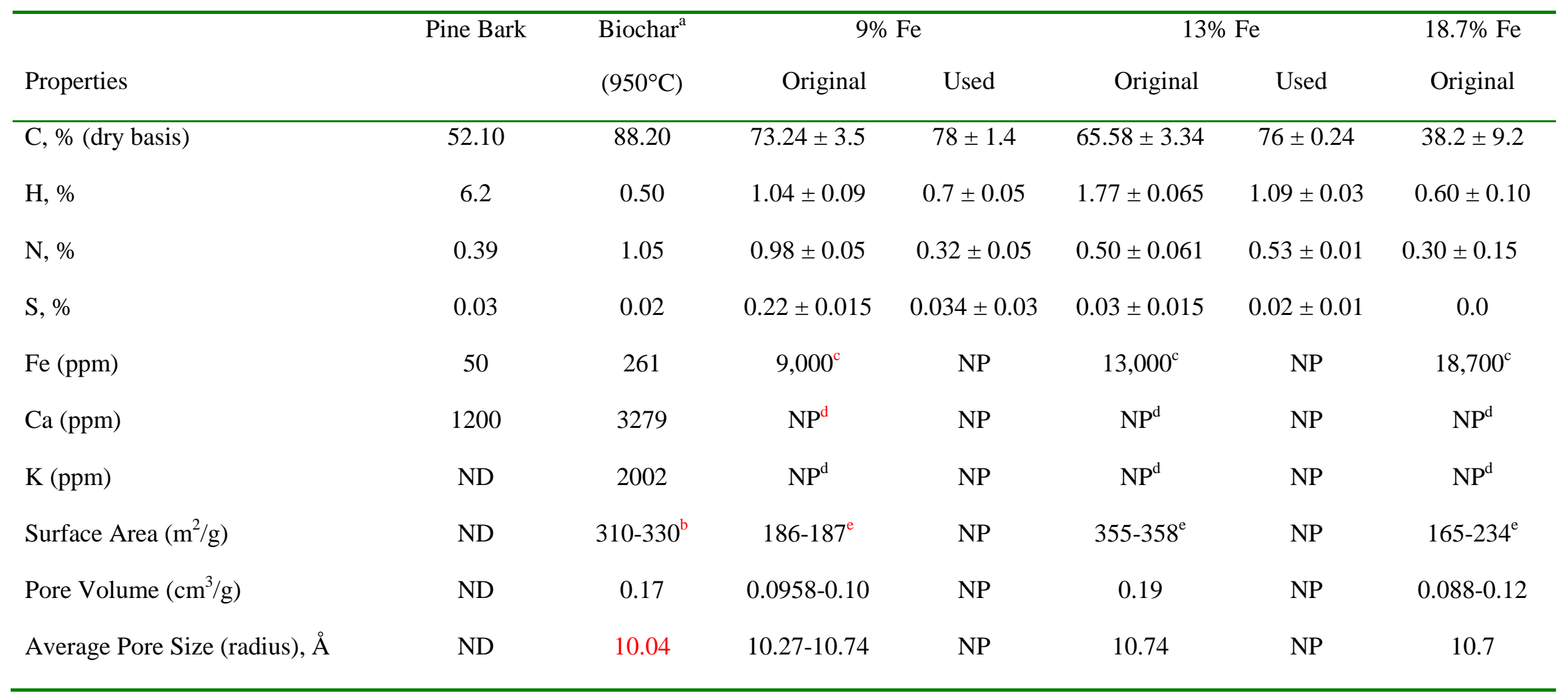

ND, not detected or below detection limits

NP, we attempted to measure surface area of these samples, but we could not successfully degas them for proper analysis

${ }^{a}$ Particle Size $(\mu \mathrm{m}): 212-420 ;{ }^{b}$ triplicate surface area analysis, but only one data point for pore volume distribution and pore size

${ }^{\mathrm{c}}$ based on the wet impregnation method; ${ }^{\mathrm{d}} \mathrm{Ca}$ and $\mathrm{K}$ assumed to be present in the Fe-biochar; ${ }^{\mathrm{e}}$ duplicates 
Table 2. Effect of temperature on fractional conversions and first order rate constants for toluene decomposition using pine bark biochar catalyst (2,500 ppmv inlet, $\left.0.09 \mathrm{~kg}-\mathrm{hr} / \mathrm{m}^{3}\right)$ and comparison with the literature.

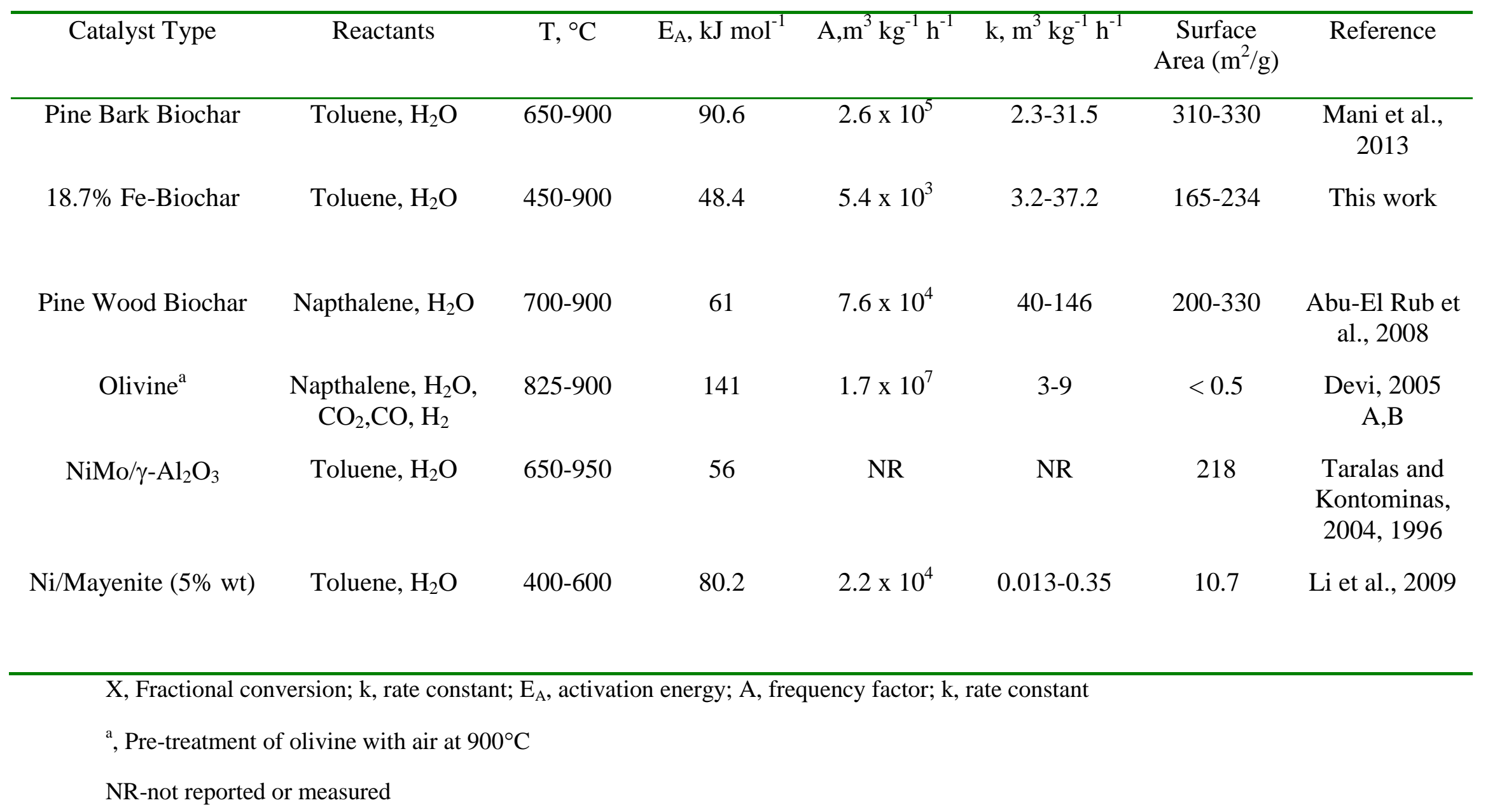


A

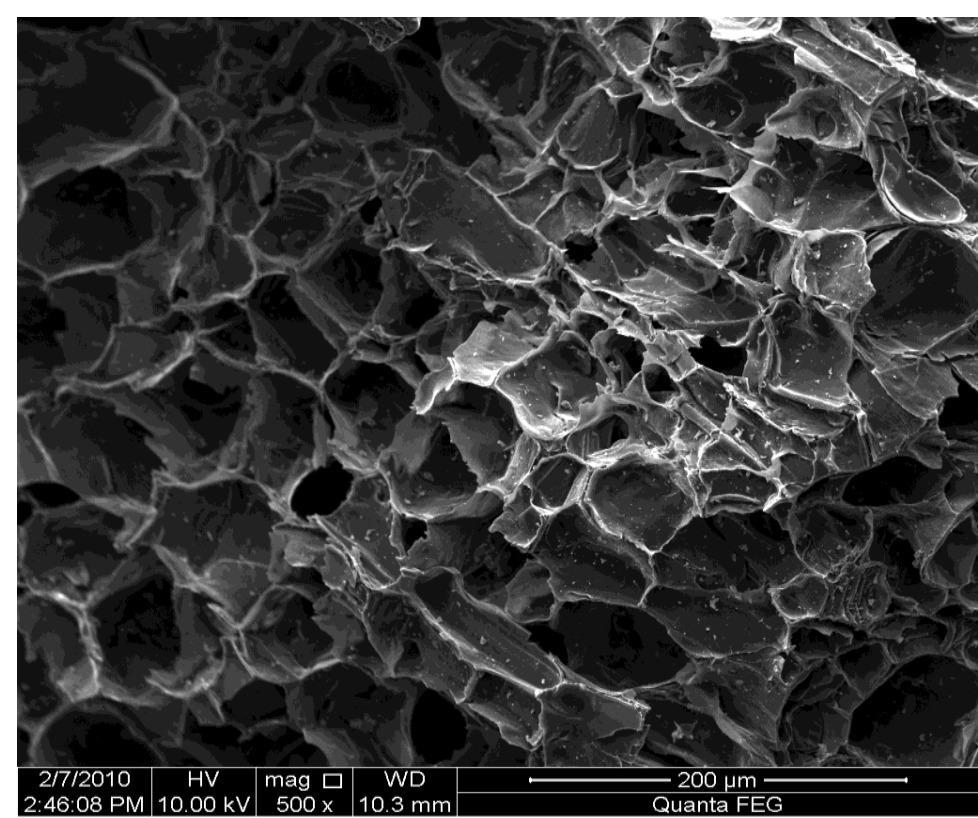

C

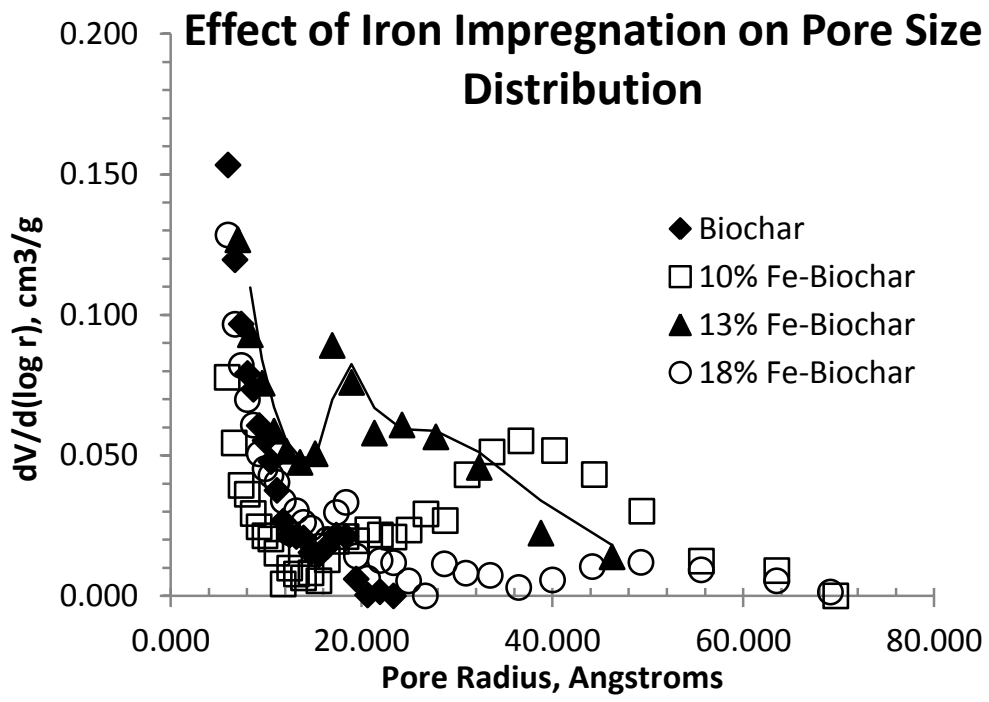

B

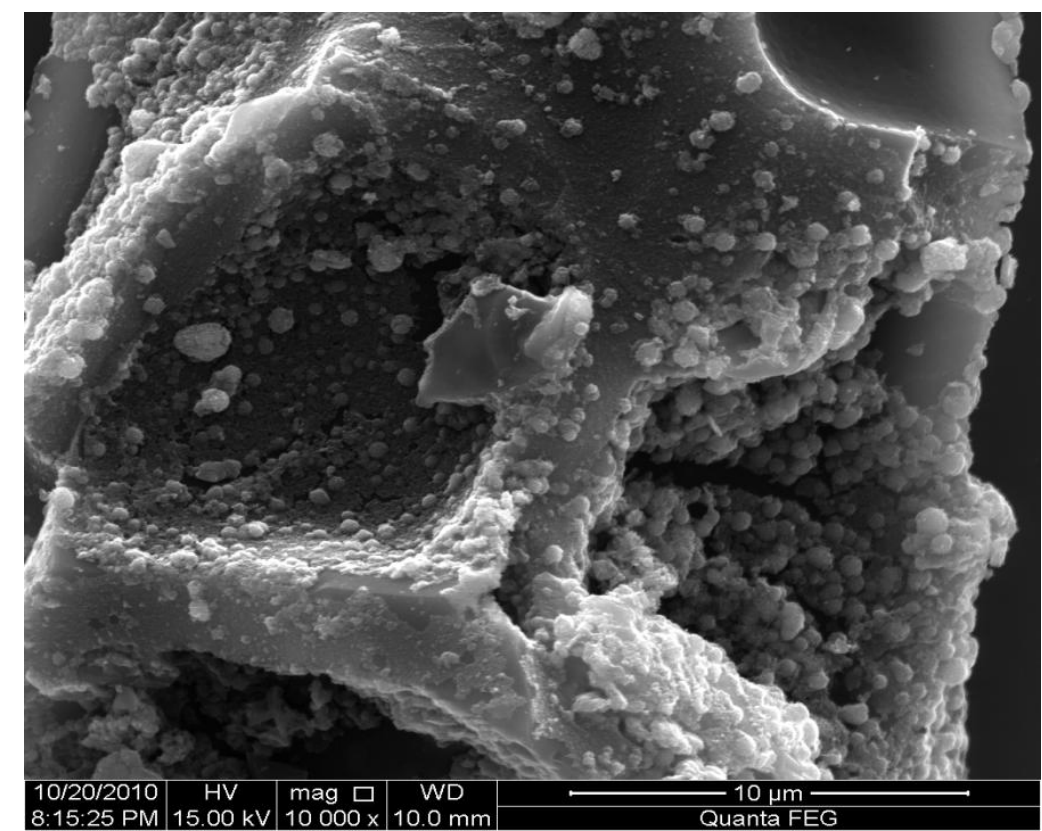

D

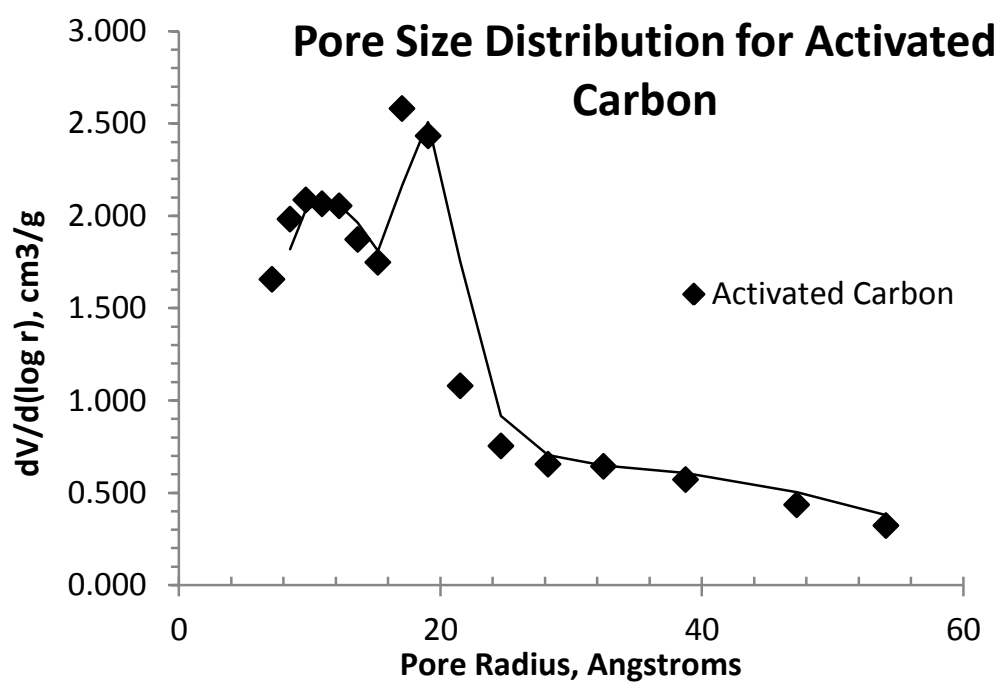

Figure 1: SEM analysis of biochar catalyst generated from pine bark (A, taken from Mani et al., 2013) by slow pyrolysis at $950^{\circ} \mathrm{C}$, resultant iron impregnated catalyst (B-18.7\% wt. \% Fe) and BJH analysis of the biochar (C) compared to activated carbon (D). The activated carbon was a MeadWestvaco granular carbon (Nuchar WV-B 20) with a surface area of $1944 \mathrm{~m} 2 / \mathrm{g}$ and presented for comparison purposes. 

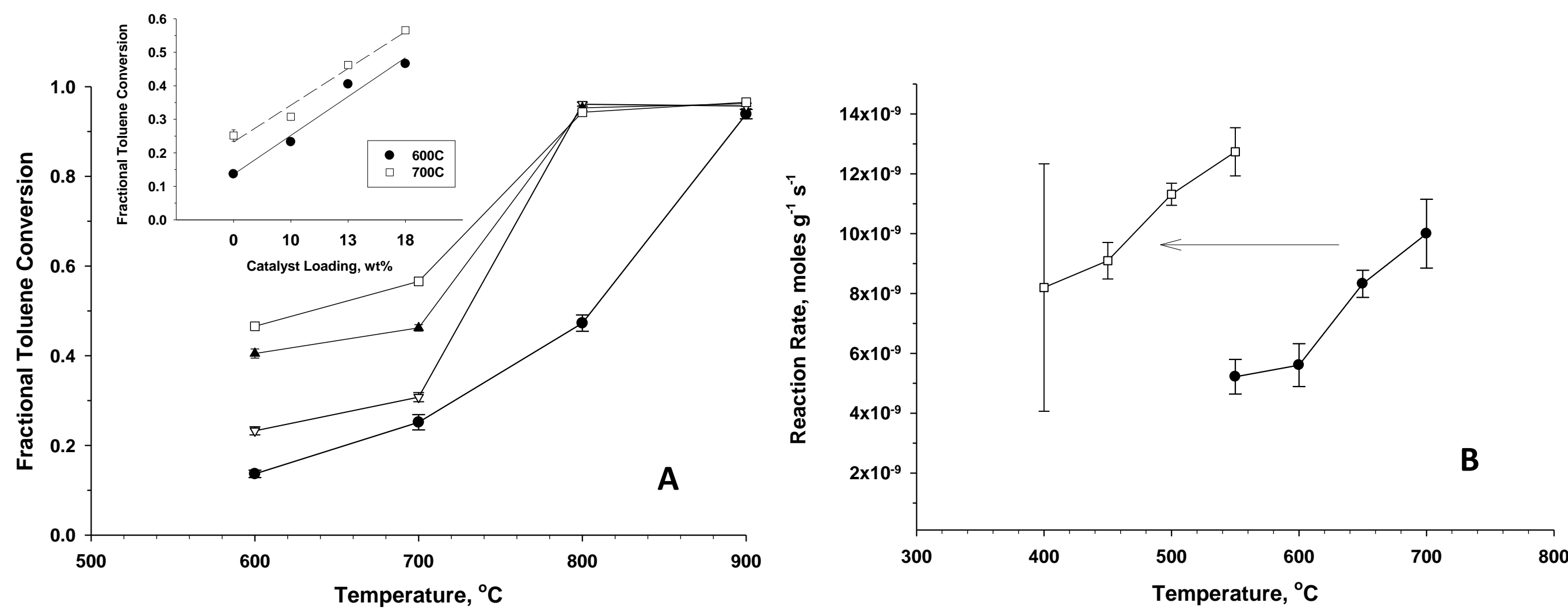

Figure 3: Effect of iron loading on toluene decomposition conversion (A) and rates (B) ( $\boldsymbol{O}$, biochar; $\nabla, 10$ wt.\%; $\boldsymbol{\Delta}, 13$ wt.\%, and $\square, 18.7$ wt.\% Fe-biochar) - inlet toluene concentration $1395 \pm 72$ ppmv for Fe-biochar and $1220 \pm 63$ ppmv for biochar in comparison of rates (B) and 2,500 ppmv for fractional conversion (A), catalyst $3.8 \mathrm{~g}$, space time $=0.09 \mathrm{~kg}-\mathrm{hr} \mathrm{m}{ }^{-3}$ (inset for part A). 


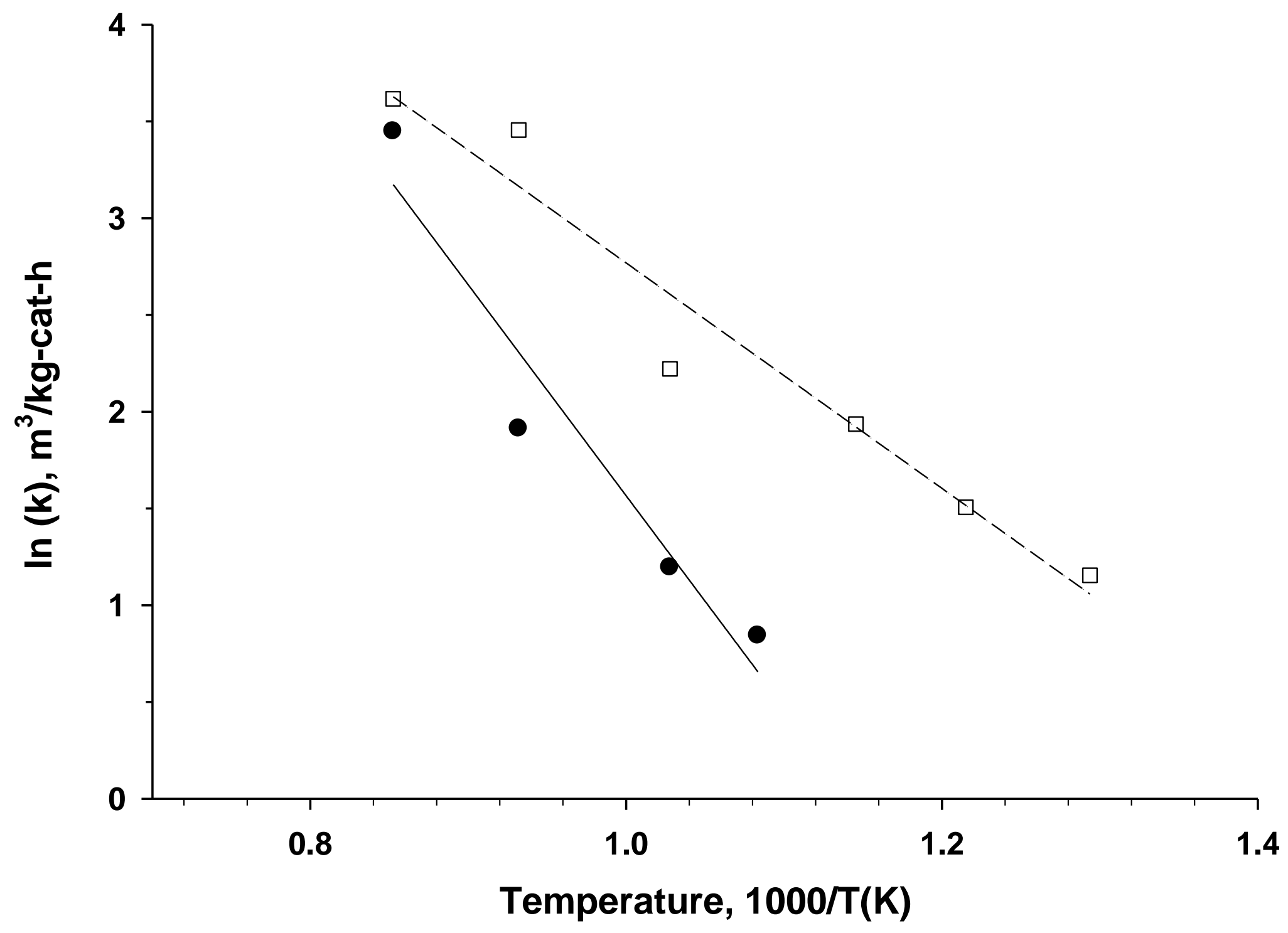

Figure 4: Effect of iron on the activation energy of the apparent first order rate constant for toluene decomposition using $18.7 \%$ iron supported biochar, $\left(\square, \mathrm{E}_{\mathrm{A}}=48.4 \pm 5.4\right.$ (stnd. error) compared to biochar only $\left(\boldsymbol{O}, \mathrm{E}_{\mathrm{A}}=91 \pm 17.3\right.$ (stnd. error) $\mathrm{kJ} / \mathrm{mole}$; data taken from Mani et al., 2013) - $3.8 \mathrm{~g}$ catalyst, $0.7 \mathrm{~L} / \mathrm{min}, \sim 2,500 \mathrm{pmv}$ inlet. 


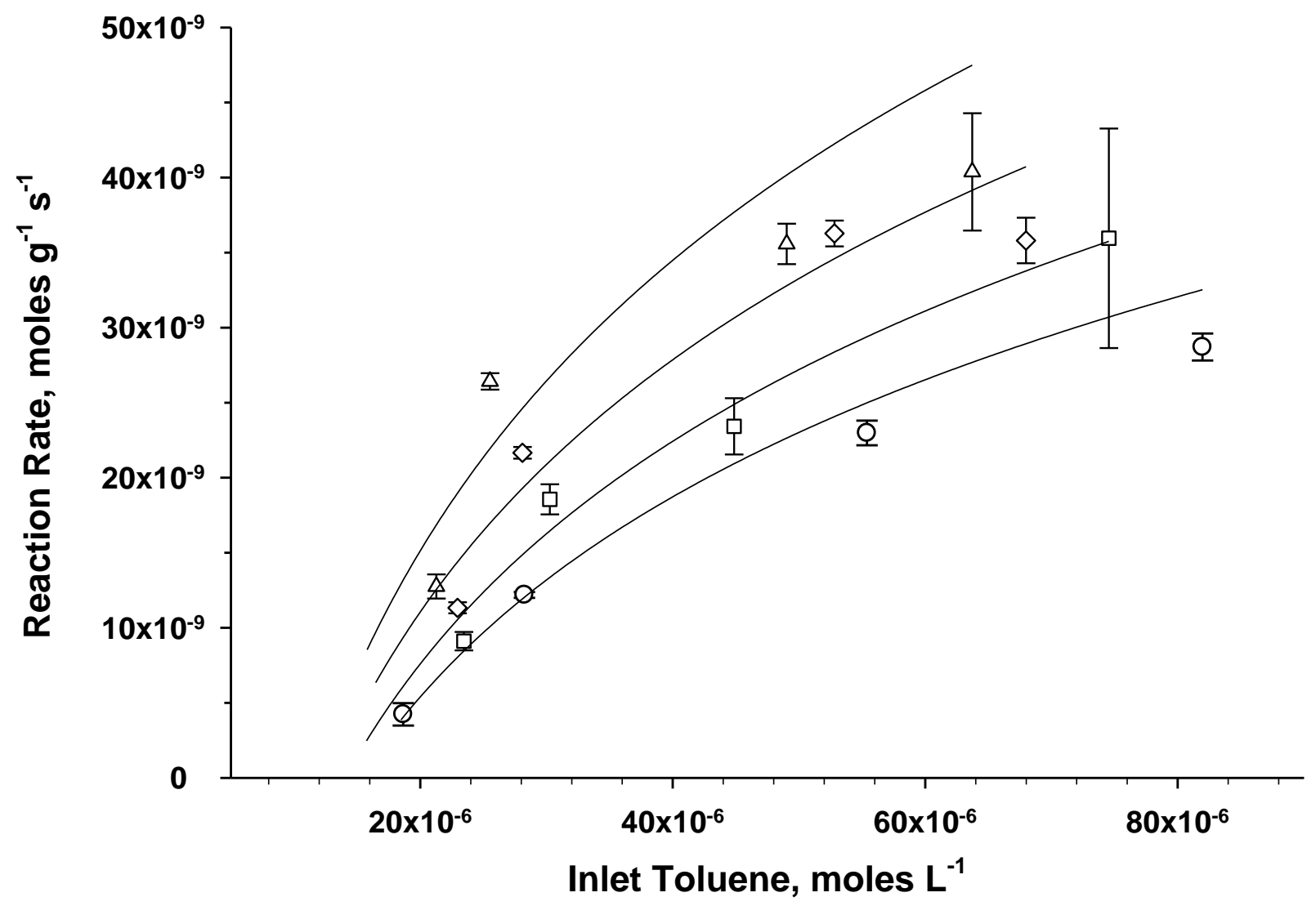

Figure 5: Effect of toluene concentration on the reaction rate for $18.7 \mathrm{wt} \%$ iron loaded catalyst at different temperatures. In some cases error bars are not visible and smaller than the symbols $\left(\bigcirc 400^{\circ} \mathrm{C}, \square 450^{\circ} \mathrm{C}, \diamond 500^{\circ} \mathrm{C}\right.$, and $\left.\triangle 550^{\circ} \mathrm{C}\right)$. 

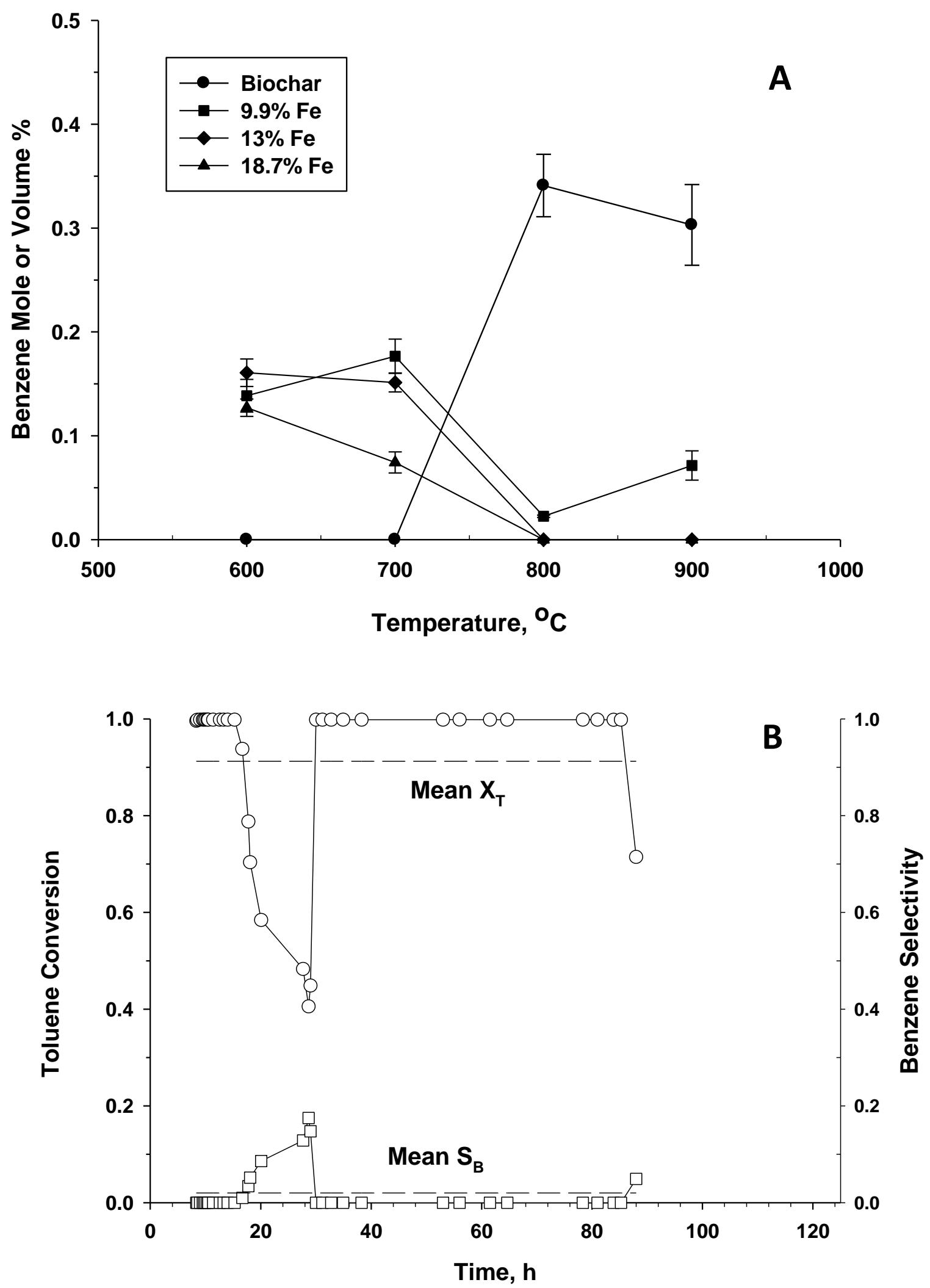

Figure 6: Effect of iron loading (wt.\%) on benzene selectivity (A: nitrogen flow $0.71 / \mathrm{min}$, toluene inlet $\sim 2500 \mathrm{ppmv}$, biochar as catalyst $3.8 \mathrm{~g}$, space time $=0.09 \mathrm{~kg}_{\text {cat }} \mathrm{h} \mathrm{m}^{-3}$ ) and time on stream toluene decomposition activity and benzene selectivity for Fe-biochar, $13 \mathrm{wt} . \% \mathrm{Fe}$ at $800^{\circ} \mathrm{C}$ (B: 2,500 ppmv, $3.8 \mathrm{~g}$ biochar, $0.09 \mathrm{~kg}_{\mathrm{cat}} \mathrm{h} \mathrm{m}^{-3}$ ). 